\title{
SUBJETIVIDADE, LIBERDADE E AÇÃ̃): APROXIMAÇÕES ENTRE A ONTOLOGIA FENOMENOLÓGICA DE SARTRE E O IDEALISMO TRANSCENDENTAL DE FICHTE
}

\section{RESUMO:}

\author{
Vinícius dos Santos ${ }^{1}$ \\ Universidade Federal da Bahia (UFBA) \\ (D) https://orcid.org/0000-0002-0752-8663
}

O artigo visa encontrar pontos de aproximação da definição de subjetividade que Sartre expõe em $O$ ser e o nada à correlata conceituação de Fichte na Doutrina-da-Ciência. Para tanto, a estratégia aqui adotada, primeiramente, é a de analisar como a noção de Eu enquanto fundamento surge no pensamento fichteano e culmina em uma teoria da razão prática que implica no primado ontológico da ação. A partir disso, será possível traçar certos pontos de convergência (e divergência) com a operação sartriana de fundamentação do cogito em uma ordem pré-reflexiva, cujo desdobramento se aproxima daquele traçado por Fichte. Numa palavra, o intuito é mostrar como o pensamento de ambos os autores resulta em uma filosofia prática cujo leitmotiv é o expurgo a qualquer índice de reificação da consciência, logo, na proclamação da liberdade absoluta do sujeito.

PALAVRAS-CHAVE: Fenomenologia; Filosofia transcendental; Idealismo; Liberdade; Subjetividade.

\section{SUBJECTIVITY, FREEDOM AND ACTION: APPROACHES BETWEEN SARTRE'S PHENOMENOLOGICAL ONTOLOGY AND FICHTE'S TRANSCENDENTAL IDEALISM}

\begin{abstract}
:
The article aims to find points of approximation on the definition of subjectivity that Sartre exposes in Being and nothingness to the analogue conceptualization from Fichte in Science of knowledge. In order to do so, the strategy adopted here, first, is to analyze how the notion of I as ground arises in the Fichtean thought and culminates in a theory of practical reason that implies in the ontological primacy of action. From this, it will be possible to draw certain points of convergence (and divergence) with the Sartrean operation of founding the cogito in a pre-reflective instância, whose deployment is close to that drawn by Fichte. In a word, the intention is to show how the thought of both authors results in a practical philosophy whose leitmotiv is the purge of any index of reification of consciousness, thus, in the proclamation of the absolute freedom of the subject.
\end{abstract}

KEYWORDS: Freedom; Idealism; Phenomenology; Subjectivity; Transcendental philosophy.

\footnotetext{
${ }^{1}$ Professor adjunto do Departamento de Filosofia da Universidade Federal da Bahia (UFBA), Bahia - Brasil. E-mail: vsantos1985@gmail.com
}

SANTOS, Vinícius dos. Subjetividade, liberdade e ação: aproximações entre a ontologia fenomenológica de Sartre e o idealismo transcendental de Fichte. Griot : Revista de Filosofia, Amargosa, Bahia, v.16, n.2, p.81-101, dezembro/2017. 
O panorama filosófico francês do entre-guerras é caracterizado, dentre outras coisas, pela recepção da filosofia alemã pós-kantiana. Destaca-se, em particular, a compreensão da subjetividade histórica e a revigoração da dialética empreendidas por Hegel, autor cuja introdução naquele território se deve aos famosos cursos ministrados na Sorbonne por Alexandre Kojève na década de 1930, bem como pela tradução de Jean Hyppolite da Fenomenologia do Espírito.

$\mathrm{Na}$ esteira dessa recepção, conquanto com menor impacto, figuras como Fichte ou Schelling passam também a figurar no horizonte do pensamento francês. Destarte, não é de se estranhar certos ecos daqueles filósofos nas teorias emergentes neste contexto, como o existencialismo de Sartre.

Nesse sentido, pode-se observar que, embora não cite Fichte em nenhum momento ao longo de $O$ ser e o nada e, mais ainda, coloque-se resolutamente contrário ao idealismo filosófico - isto é, de certa interpretação do idealismo, cujo protótipo, para Sartre, é Berkeley -, pode-se encontrar, para além das evidentes diferenças, certa aproximação entre o pensamento de Sartre e aquele do filósofo alemão em pelo menos dois pontos essenciais, a saber: a apreensão da consciência-desi como resultado de uma intuição absoluta que seria o único ponto de partida possível para uma filosofia consequente; e a definição dessa consciência como ato puro, isto é, como liberdade.

Para além dessa contingência contextual, há ainda, segundo indica Tom Rockmore (cf. ROCKMORE, 1995, p. 210-1), um interlocutor indireto dessa problemática, que permeia a obras dos dois autores aqui considerados: Descartes. Primeiro, explica o comentador, ao conferir privilégio à subjetividade como fundamento da investigação filosófica ("científico-transcendental" ou fenomenológica); mas, na sequência, na recusa à assimilação cartesiana entre sujeito e pensamento, como se verá na sequência. Com efeito, como se buscará mostrar neste artigo, tanto Fichte quanto Sartre se colocam a tarefa de conservar a primazia da subjetividade, enraizando-a, porém, em um registro que transcenda seu uso exclusivamente epistemológico, superando, neste gesto, a coisificação advinda da definição cartesiana da res cogitans.

Desse modo, pretende-se explicitar como o entendimento de Sartre acerca da subjetividade remete à correlata conceituação fichteana, desembocando em uma filosofia prática cujo leitmotiv é o expurgo de qualquer índice de reificação da consciência. Logo, na proclamação da liberdade absoluta do sujeito ou na primazia da razão prática, do fazer, sobre a razão teórica, sobre o ser.

Para tanto, a estratégia aqui adotada, primeiramente, é a de analisar como a noção de Eu enquanto fundamento surge no pensamento fichteano e culmina em uma teoria da razão prática que implica no primado ontológico da ação. A partir disso, será possível traçar certos pontos de convergência (e divergência) com a operação sartriana de fundamentação do cogito em uma instância pré-reflexiva, cujo desdobramento prático se aproxima daquele traçado por Fichte.

Conquanto possa se inscrever à distância na tradição inaugurada pelo cartesianismo, como dito no início, é notório que a relação de Fichte com o tema da

SANTOS, Vinícius dos. Subjetividade, liberdade e ação: aproximações entre a ontologia fenomenológica de Sartre e o idealismo transcendental de Fichte. Griot : Revista de Filosofia, Amargosa, Bahia, v.16, n.2, p.81-101, 
subjetividade se dá fundamentalmente pela mediação da filosofia de Kant. Pode-se perceber essa mediação pelo agenciamento de dois movimentos complementares. Em primeiro lugar, à luz do $§ 16$ da Crítica da razão pura, na qual se anuncia o problema da apercepção transcendental ${ }^{2}$ como núcleo da razão teórica. Segundo, e mais relevante, o problema da liberdade, definido da Crítica da razão prática. Mais precisamente: é o primado kantiano da razão prática que empurra Fichte para a constituição inicial da Doutrina-da-ciência e, em consequência, na busca por um fundamento para o sistema que ultrapasse a limitação do sujeito transcendental de Kant.

Desnecessário reafirmar o quanto a filosofia kantiana determina o horizonte dos debates filosóficos alemães nas últimas décadas do século XIX. Para o intento deste artigo, basta apenas pontuar que a unidade da apercepção, fiadora da possibilidade da representação, mostrara-se insuficiente aos olhos de seguidores e críticos do kantismo. Reinhold, por exemplo, entendia que a filosofia crítica exigia a concepção de um princípio unificador que não poderia ser encontrado no Eu transcendental. Antes, seria no próprio conceito de representação, enquanto unificação de consciência e objeto, matéria e forma, que se encontraria aquele princípio. Schulze, por sua vez, posicionando-se na esteira do ceticismo de Hume, rebate a filosofia crítica indicando a incongruência da relação entre a coisa-em-si e conhecimento proposta por Kant.

Para Fichte, o ceticismo de Schulze não invalida a filosofia crítica, mas exige - como Reinhold tentou, sem sucesso - a busca por fundamento. Nesse sentido, para Fichte, não se trata de recusar a objeção kantiana ao conhecimento da coisa-em-si: todo conhecimento do objeto, admite, é inevitavelmente mediado pelo aparato cognitivo do sujeito. $\mathrm{O}$ que se trata, na verdade, é estabelecer o princípio a partir do qual é possível haver um conhecimento sintético a priori da série de aparições ${ }^{3}$. Este é o horizonte do programa da primeira versão da Wissenschaftslehre, escrita em Jena, à qual este artigo se circunscreverá.

“Temos de procurar", diz o autor nas primeiras linhas do texto, "o princípio absolutamente primeiro, pura e simplesmente incondicionado, de todo saber humano" (FICHTE, 1980, p. 43 - I, 91). Atingir este objetivo é o passo decisivo peara elevar o conhecimento filosófico ao estatuto de um sistema, de ciência ${ }^{4}$. Ou seja, a filosofia transcendental exige um primeiro princípio deve ser apodítico: sua certeza e veracidade devem convir a todas as proposições subsequentes, precisamente por conta de seu caráter sistêmico. Antes de um fim em si mesmo, portanto, este caráter é o meio pelo qual se torna possível atingir a certeza que o saber científico exige.

\footnotetext{
2 Vale lembrar, na referida passagem, Kant dizia: “O eu penso deve poder acompanhar todas as minhas representações; se assim não fosse, algo se representaria em mim, que não poderia, de modo algum, ser pensado, que o mesmo é dizer, que a representação ou seria impossível ou pelo menos nada seria para mim" (B131-2).

3 Tal como também buscara Jacobi (cf. IBER. In: IBER et al., 2007, p. 24).

4 Fichte entende ciência, nas palavras de Will Dudley, como "um corpo de conhecimento proposicional que possui forma sistemática, e define sistemático como a unificação de todas as proposições através de um primeiro princípio único" (DUDLEY, 2007, p. 75).
}

SANTOS, Vinícius dos. Subjetividade, liberdade e ação: aproximações entre a ontologia fenomenológica de Sartre e o idealismo transcendental de Fichte. Griot : Revista de Filosofia, Amargosa, Bahia, v.16, n.2, p.81-101, 
Consequentemente, este princípio - se houver - não pode ser resultado de uma dedução. Não pode ser provado, porque o resultado da prova depende da aceitação das premissas que, neste caso, precederiam o próprio princípio inaugural que se busca. Mas, se é deste primeiro princípio que todas as demais proposições que constituem o sistema podem ser extraídas, quando seria possível saber que a dedução está completa? Ou seja, como estar seguro de que se esgotou tudo aquilo que é possível depreender cientificamente? Esclarece Dudley:

\begin{abstract}
O único modo de descartar a possibilidade de proposições adicionais serem acrescentadas ao sistema, conclui Fichte, é se a dedução retorna ao seu ponto de início, garantindo, então, que quaisquer inferências subsequentes apenas irão retraçar os passos já dados, mais do que demonstrar algo novo. A filosofia científica deve, por conseguinte, formar um sistema fechado e circular, partindo de um único princípio fundacional e finalmente retornando a ele através de cuidadosos passos dedutivos que assegurem a completude do corpo resultante de proposições (DUDLEY, 2007, p. 76).
\end{abstract}

Contudo, resta ainda definir como é possível um objeto para a filosofia enquanto doutrina-da-ciência. Na Refutação do idealismo, Kant assinalava que a "a experiência interna em geral só é possível mediante a experiência externa em geral" (B279). A investigação da consciência conduz à necessidade da existência do mundo exterior - real ou imaginário - enquanto objeto para esta consciência ${ }^{5}$. Fichte, porém, recusa esse passo, na medida em que Kant, aqui, poderia ser alvo das mesmas objeções que dirigira ao argumento ontológico cartesiano.

Esse ponto merece certo cuidado explicativo, porque Fichte constrói uma argumentação calcada no kantismo que, a rigor, no entanto, parece se afastar dele em um ponto sensível para a filosofia crítica.

Segundo a Doutrina da ciência, a filosofia deve fornecer o "fundamento" (Grund) de toda experiência. Falar em experiência significa abordar a relação entre uma coisa da qual se tem experiência e um sujeito que tem experiência dessa coisa. Em termos epistemológicos, significa dar conta da realidade da representação. $O$ autor assinala dois modos de entender essa relação. O dogmatismo (cujo protótipo aqui é Espinosa) busca sua chave explicativa na coisa em si mesma, enquanto o idealismo dirige-se ao sujeito da experiência. Segundo Fichte, por operarem em registros diferentes, desde premissas divergentes, ambos são, dentro de sua lógica, incapazes de refutar um ao outro. Contudo, o dogmatismo apresenta um entrave ainda mais grave: ao postular um mundo independente da consciência, ele se torna necessariamente um materialismo e, ipso facto (para Fichte), um mecanicismo incapaz de dar conta do que é a consciência. Logo, inapto a esclarecer o ponto elementar de toda a experiência: a representação, o fato de haver consciência-dealgo $^{6}$. Não há, na concepção fichteana do dogmatismo (ou, se se preferir, do

\footnotetext{
${ }^{5}$ Embora se trate de um ponto nodal da argumentação, o agenciamento kantiano é menos evidente do que pode parecer - fato, de resto, reconhecido pelo próprio (cf. KANT, B XXXIX-XLI), como observa Tom Rockmore (ROCKMORE, 1995, p. 217-8).

6 Sabe-se que a fenomenologia, da qual o jargão "consciência-de-algo" foi tirado, nasce contra a ideia clássica de representação. Contudo, o gesto fichteano, ainda que atrelado ao horizonte do kantismo, de certo modo antecipa a exigência de uma relação intrínseca entre consciência e mundo que Husserl buscará desvelar através da noção de intencionalidade e da qual Sartre se apropriará.
}

SANTOS, Vinícius dos. Subjetividade, liberdade e ação: aproximações entre a ontologia fenomenológica de Sartre e o idealismo transcendental de Fichte. Griot : Revista de Filosofia, Amargosa, Bahia, v.16, n.2, p.81-101, 
materialismo), passagem possível entre a coisa-em-si e o fenômeno imaterial da consciência. Resta, por conseguinte, adotar a única via possível para a filosofia, a única a dar conta do fenômeno da consciência: a via idealista ${ }^{7}$.

Fichte reconhece que Kant estabeleceu como tarefa primária da filosofia explicar como a consciência pode ser a fonte das condições transcendentais de sua experiência interna e do mundo externo. Entretanto, a Crítica da razão pura teria falhado na dedução das categorias do entendimento - extraídas dos juízos empíricos - porque não avançou na compreensão do Eu como princípio unificador e autoreferente do sistema ${ }^{8}$. Numa palavra, para Fichte, Kant forneceu o princípio do sistema, mas não o próprio sistema. Desse modo, o filósofo se propõe não apenas a aprimorar a dedução kantiana, mas restabelecer um programa a partir do qual seja possível oferecer a priori os traços elementares da experiência como produtos da atividade da própria consciência enquanto consciência-de-si.

Mas, convém questionar: qual a real possibilidade de execução desse programa? A citação a seguir, extraída da primeira Introdução à Doutrina da Ciência, é esclarecedora:

[O idealismo] mostra que aquilo que é estabelecido como princípio fundamental e diretamente demonstrado na consciência é impossível, a menos que algo mais ocorra conjuntamente, e que este algo mais é impossível a menos que uma terceira coisa também ocorra, e assim por diante, até que as condições daquilo que foi primeiramente exibido sejam completamente exauridas e que este último seja totalmente inteligível acerca de sua possibilidade. Seu curso é uma progressão continuada do condicionado à condição. Cada condição, na sequência, torna-se um condicionado, cuja condição deve ser procurada. Se a hipótese do idealismo é correta e o raciocínio na dedução é válido, o sistema de todas as apresentações necessárias ou da inteireza da experiência (...) deve emergir como o resultado final, como a totalidade das condições da premissa original (FICHTE, 1991, p. 25-6 - I, 446).

Embora seja vivida imediatamente, a consciência-de-si requer um ato de auto-constituição. Importa notar como este ato é pensado por Fichte em termos de uma intuição intelectual. Afinal, Kant havia expressamente rejeitado a possibilidade de uma intuição deste tipo. Fichte, porém, argumenta que Kant, ao rejeitar a intuição intelectual, tinha em mente apenas a impossibilidade de conhecimento da coisa-em-si - gesto que, como dito, Fichte aceita -, mas não ao ato originário de apreensão de si, que jamais poderia se dar como conhecimento dedutivo (porque imediato), ou por intuição sensível, posto que os sentidos são incapazes de captar algo como o Eu. "A intuição intelectual aludida na Doutrina da Ciência não se refere

\footnotetext{
7 Importa destacar que nem sempre Fichte adota o termo "idealismo" para se referir à sua filosofia. Em algumas oportunidades, o filósofo classifica seu pensamento tão somente como "doutrina da ciência", "ideal-realismo" ou "real-idealismo", e ainda como "realismo autêntico". Neste artigo, optou-se por usar a classificação que o próprio Fichte emprega para sua teoria na Doutrina-da-ciência de 1794, em oposição ao dogmatismo e ao materialismo.

8 Assim, para Fichte, essas categorias, tanto quanto as intuições puras da sensibilidade, serão resultados da "imaginação produtiva", ou seja, a atividade permanente do Eu que põe seu objeto enquanto representação, como se mostrará mais adiante. Nesse sentido, vale ainda destacar, é que a imaginação pode ser interpretada como o núcleo do sistema fichteano (cf. TORRES FILHO, 1975).
}

SANTOS, Vinícius dos. Subjetividade, liberdade e ação: aproximações entre a ontologia fenomenológica de Sartre e o idealismo transcendental de Fichte. Griot : Revista de Filosofia, Amargosa, Bahia, v.16, n.2, p.81-101, 
à existência, mas à ação, e simplesmente não encontra menção em Kant (a menos, talvez, sob o título de apercepção pura)" (FICHTE, 1991, p. 46 - I, 472).

Eis que, desse modo, reaparece o núcleo do idealismo transcendental kantiano, qual seja, o já mencionado §16 da Crítica da razão pura. Para Fichte - o que, diga-se, é bastante questionável da perspectiva interna ao kantismo - a "intuição intelectual" corresponde ao gesto pelo qual Kant indicava a condição de possibilidade da intuição sensível e do pensamento conceitual como a unidade do sujeito consciente, da apercepção. Unidade essa que, convém acrescentar, requer um ato (Tathandlung) de espontaneidade pura que, se por um lado não é objeto de experiência, por outro, é aquilo sem o qual nenhuma experiência seria possível. Não se trata de um recurso epistemológico, mas do fundamento último - existencial, pode-se dizer, no sentido que este termo assumiria na filosofia mais tarde - das capacidades cognitivas e práticas do sujeito racional. Numa palavra, trata-se de estabelecer o Eu como pura atividade livre.

A intuição intelectual é o único ponto de partida sólido para toda a filosofia. Por esta razão, podemos explicar tudo que ocorre na consciência; e, ainda mais, apenas por esta razão. Sem a consciência-de-si não há qualquer consciência. Contudo, a consciência-de-si só é possível da maneira indicada: Eu sou simplesmente ativo (FICHTE, 1991, p. 41 - I, 466).

Assim, conforme esclarece Nicolai Hartmann,

em oposição ao modo de considerar o agente kantiano, a idealidade das condições transcendentais do conhecimento eleva-se aqui a um plano mais alto do pensamento filosófico. É dum plano inferior que Kant recolhe as leis em questão [as leis da consciência - V.S.], obtendo-as a partir da sua aplicação (à experiência), não da essência da própria inteligência. Em Kant são dadas as aplicações e com elas as próprias leis. Mas o verdadeiro idealismo apenas pode pressupor como dado a própria essência da inteligência, que é atividade pura. Kant não mostra como se origina o sujeito, mas só as suas qualidades e relações. Mas estas podem compreender-se muito bem na sua gênese se se recuar à sua origem que, por sua vez, já não reside em leis dadas, mas sim numa livre concessão de leis. Procurar uma matéria dada é então supérfluo, pois o objeto não é senão a síntese original de todas as relações. Esta posição filosófica básica não pode deduzir-se, só pode ser imediatamente "verificada". Porque o último reduto de todas as determinações, assim como a unidade da sua síntese, reside na atividade da inteligência (HARTMANN, 1983, p. 61).

É este agenciamento que cabe agora detalhar.

II

Se o objetivo é fornecer o primeiro princípio incondicionado do conhecimento, forçoso é constatar que não há conhecimento sem a emissão de juízos que, por sua vez, devem obedecer a critérios lógicos - critérios cuja veracidade seja evidente já para a consciência empírica. Assim, remetendo o leitor a um texto anterior, o $\S 7$ de

SANTOS, Vinícius dos. Subjetividade, liberdade e ação: aproximações entre a ontologia fenomenológica de Sartre e o idealismo transcendental de Fichte. Griot : Revista de Filosofia, Amargosa, Bahia, v.16, n.2, p.81-101, 
Sobre o conceito da Doutrina da Ciência ${ }^{9}$, Fichte toma como ponto de partida as leis mais evidentes da lógica.

Na esteira de Kant e Wolff, Fichte identifica que o mais primordial dos princípios lógicos é o de identidade $(\mathrm{A}=\mathrm{A})$, do qual todos os demais derivariam (cf. FICHTE, 1980, p. 44 - I, 93). Não obstante, este primeiro princípio é puramente formal, pois incapaz de fornecer um conteúdo para o juízo. Limita-se a declarar que, se $\mathrm{A}$ existe, então $\mathrm{A}=\mathrm{A}$. Com efeito, a única necessidade nesse princípio é sua conexão lógica: “se..., então". Mas, esta conexão - que o filósofo chamará de X - só existe para a consciência que a põe (setzen) ${ }^{10}$. Quer dizer, quem põe X é o Eu, que além dela põe também o A. Disso decorre que, se o princípio lógico supremo é posto, não pode ser originário. O princípio originário só pode, então, ser o próprio Eu ponente.

Portanto, é posto pelo eu, mediante X: $A$ é, pura e simplesmente, para o eu
que julga, e exclusivamente por força de seu estar-posto no eu em geral; isto é, é
posto que no eu - seja agora em particular o que põe, ou o que julga, ou o
que quer que ele seja - há algo que é sempre igual a si, sempre um e o
mesmo; e esse X pura e simplesmente posto pode também exprimir-se
assim: eu =eu; eu sou eu (FICHTE, 1980, p. 45 - I, 94).

A = A é um julgamento; logo, uma atividade da consciência humana. Se ele se funda na autoposição do Eu, pode-se concluir que esta autoposição "é a sua atividade pura. $\mathrm{O}$ eu põe a si mesmo e é, em virtude desse mero pôr-se por si mesmo; e vice-versa: o eu é e, em virtude de seu mero ser, põe seu ser" (FICHTE, 1980, p. 46 $\mathrm{I}, 96)$. O Eu, portanto, é simultaneamente agente e produto da ação; é aquilo que permite e sustenta a posição de $\mathrm{A}$ tanto à esquerda quanto à direita do referido juízo.

Entretanto, o princípio da Doutrina da Ciência não poderia ser apenas certo em si mesmo, enquanto oferece a forma da certeza de qualquer outra proposição. Também deve conter em si todo conteúdo possível da mesma. Daí que este princípio supremo só pode ser o "Eu sou".

Neste gesto, Fichte esvazia o Eu de qualquer caráter substancial, qualquer traço de reificação (Verdinglichung); torna-o puro ato tético, identidade entre sujeito e objeto. Não, porém, como uma identidade abstrata, formal. $\mathrm{O} \mathrm{Eu}=\mathrm{Eu}$ é a identidade dinâmica do princípio de autoposição, a possibilidade do ser-para-si da consciência. O Eu se põe apenas por existir e existe por ser meramente posto. Em outras palavras, aquele "cujo ser (essência) consiste meramente nisto: que ele põe a si mesmo como sendo é o eu, como sujeito absoluto. Assim que se põe, ele é, e assim que $e ́$, ele se põe; e portanto, para o eu, o eu é pura e simplesmente" (FICHTE, 1980, p. $46-\mathrm{I}, 97)$.

Destarte, Fichte inverte o sentido entre ser e ação legado pela metafísica clássica. Pois, se, para a última, o agir dependia do ser, agora se passa o contrário: o ser depende da ação concreta do Eu absoluto, que não se reduz ao pensamento, como

${ }^{9} \S 7$. Como se relaciona a doutrina-da-ciência, como ciência, com seu objeto (cf. FICHTE, 1980, p. 28 I, 70-80).

${ }^{10}$ Como esclarece Dudley, quando Fichte diz que a consciência setzt um objeto, a ideia que se pretende passar é a de que "tornar-se consciente de um objeto exige uma atividade da parte do sujeito, um focar que fixa ou estabelece o objeto como o centro da atenção" (DUDLEY, 2007, p. 88).

SANTOS, Vinícius dos. Subjetividade, liberdade e ação: aproximações entre a ontologia fenomenológica de Sartre e o idealismo transcendental de Fichte. Griot : Revista de Filosofia, Amargosa, Bahia, v.16, n.2, p.81-101, 
em Descartes, ou a um expediente epistemológico, como a apercepção pura em Kant. O conhecimento funda-se na existência ativa da consciência-de-si. Pela primeira vez na história da filosofia, o Eu é tomado como absoluto (cf. IBER. In: IBER, 2007, p. $25)$.

\begin{abstract}
Nossa proposição, como princípio absoluto de todo saber, foi apontada por Kant em sua dedução das categorias, mas ele nunca a estabeleceu determinada como princípio. Antes dele, Descartes propôs uma semelhante: cogito, ergo sum, que não deve, justamente, ser a premissa menor e a conclusão de um silogismo cuja premissa maior fosse: quodcumque cogitat, est [tudo o que pensa, existe - V.S.]; e que ele pode muito bem ter considerado como fato imediato da consciência. Então ela significaria tanto quanto cogitans sum, ergo sum (como nós diríamos, sum, ergo sum). Mas, nesse caso o acréscimo cogitans é totalmente supérfluo; não é de modo nenhum a essência, mas apenas uma determinação particular do ser; e há, além dessa, muitas outras determinações de nosso ser (FICHTE, 1980, p. 48 - I, 99-100).
\end{abstract}

III

A descoberta deste primeiro princípio no entanto, ainda é insuficiente. Resta, afinal, esclarecer como pode surgir um mundo - isto é, um objeto - para o Eu enquanto sujeito absoluto.

Para encontrar o segundo princípio do conhecimento, Fichte procede de modo análogo ao que foi experimentado anteriormente. Ou seja, de um "fato da consciência empírica" cuja validade pareça inconteste: a proposição $-A$ não $=A$ (não A não é igual a A). Trata-se, agora, do princípio de oposição (Satz des Gegensetzens), ou de contraposição.

Ao julgar, diz o filósofo, o sujeito distingue o objeto (A) daquilo que é seu outro (não-A). Porém, se o primeiro princípio estabeleceu que a única coisa posta é o Eu, é preciso que o ato de oposição permita afirmar uma distinção entre esse Eu e seu outro, isto é, o não-Eu.

Tão certo quanto aparece entre os fatos da consciência empírica a aceitação incondicionada da certeza absoluta da proposição: $-A$ não $=A$, - ao eu é oposto pura e simplesmente um não-eu. Tudo o que acabamos de dizer do opor em geral deriva-se desse opor originário; e vale, portanto, para ele, originariamente; assim, esse opor originário é pura e simplesmente incondicionado segundo a forma, mas condicionado segundo a matéria. E assim estaria encontrado também o segundo princípio de todo saber humano (FICHTE, 1980, p. 51 - I, 104).

Desse modo, considerando-se tão somente o caráter formal do ato de opor, isto é, a oposição entre Eu e não-Eu, na medida em que ambos são matéria desse ato de opor, obtém-se a proposição lógica do opor. Dessa proposição formalmente apreendida, na qual do ser oposto passa-se ao não-Eu, deduz-se a categoria da negação (cf. FICHTE, 1980, p. 52 - I, 105).

Não obstante, o estabelecimento do segundo princípio cria uma dificuldade. Ele afirma que a consciência põe atualmente o não-Eu. Mas, de acordo com o

SANTOS, Vinícius dos. Subjetividade, liberdade e ação: aproximações entre a ontologia fenomenológica de Sartre e o idealismo transcendental de Fichte. Griot : Revista de Filosofia, Amargosa, Bahia, v.16, n.2, p.81-101, 
princípio anterior, o único objeto da consciência é o próprio Eu. Logo, considerandose que a ato de pôr refere-se a um único objeto atual, o segundo princípio anula, logicamente, o primeiro - e vice-versa. Neste caso, como atesta Dudley, a única solução "é reconhecer que a consciência deve ser capaz de por o Eu e o não-Eu simultaneamente e, desse modo, atribuir atualidade a cada um deles, o que implica em reconhecer que cada um é limitado ou determinado pelo outro" (DUDLEY, 2007, p. 90).

O ponto a se destacar aqui é a ideia de limitação ou de determinação. É ela que permite a síntese entre Eu e não-Eu - ação cujo princípio unificador deve ser acolhido na identidade da consciência absoluta, tal como reza o primeiro princípio ${ }^{11}$.

Eu e não-Eu, enquanto objetos atuais, limitam-se mutuamente (cf. FICHTE, 1980 , p. $53-\mathrm{I}, 108)$ :

Limitar algo significa: suprimir sua realidade por negação, não
inteiramente, mas apenas em parte. Por conseguinte, no conceito de limites,
além da realidade e da negação, está contido ainda o de divisibilidade (de
quantificabilidade em geral; não, justamente, de uma quantidade
determinada) (FICHTE, 1980, p. $54-\mathrm{I}, 108-9)$.

Destarte, tanto Eu quanto não-Eu são postos pela consciência absoluta como divisíveis. "O total daquilo que é certo incondicionalmente, e pura e simplesmente, está agora esgotado; e eu exprimiria na seguinte fórmula: Eu oponho, no eu, ao eu divisível, um não-eu divisivel" (FICHTE, 1980, p. 55 - I, 110). Vale sublinhar que é a noção de divisibilidade (Teilbarkeit), tal como empregada aqui, que permite sustentar que ambos os objetos postos têm de ser negados parcialmente, bem como afirmados parcialmente. Não se trata de uma negação absoluta - como será o néant sartriano em relação ao Em-si - mas de uma negação determinada.

Assim, a categoria de determinação surge quando se considera a espécie de ação delimitadora promovida pelo terceiro princípio: uma determinação recíproca (Wechselbestimmung) entre Eu e não-Eu (cf. FICHTE, 1980, p. 55; p. 67 - I, 111 e ss.; I, 131), na qual ambos são postos sem se anularem mutuamente. Dessa relação resultam tanto ações antitéticas, isto é, ações nas quais se procura características iguais em elementos opostos, quanto ações sintéticas, ou seja, aquelas nas quais se busca, nos elementos opostos, características iguais. Dito de outro modo, na primeira busca-se um dado distintivo (por exemplo: a caneta não é um móvel), ao passo que, na última, tem-se como meta um fundamento referencial (por exemplo: a

\footnotetext{
11 Conforme Nicolai Hartmann: “Ora bem, o 'ponto de reunião dos opostos' não pode construir-se arbitrariamente; pelo contrário, só é possível procurar como já existente, quer dizer, demonstrar que ele está já contido "na consciência dos opostos'; com o que, de novo, o tipo do processo demonstrativo se revela abertamente igual ao anterior. Mas a razão não necessita de se preocupar com semelhante demonstração; pois, só por si, o fato de que ela, na medida em que é uma e idêntica, produziu tanto a tese como a antítese, garante também que é capaz da sua reunião. Nesta fase do raciocínio, trata-se apenas de tornar consciente o ponto de síntese já existente. Se se fecha o círculo de tese, antítese e síntese, a dedução progride de maneira que o resultado da síntese se pode interpretar outra vez como uma nova tese a que se opõe uma nova antítese. Assim, tem de prosseguir o processo até que tenha percorrido a série dos elementos compreendidos no primeiro princípio e tenha regressado substancialmente a ele" (HARTMANN, 1983, p. 65).
}

SANTOS, Vinícius dos. Subjetividade, liberdade e ação: aproximações entre a ontologia fenomenológica de Sartre e o idealismo transcendental de Fichte. Griot : Revista de Filosofia, Amargosa, Bahia, v.16, n.2, p.81-101, 
mesa é um móvel). Ambas as atividades desdobram-se da ação tética, em que o agente é posto pura e simplesmente por si mesmo.

IV

O estabelecimento dos três primeiros princípios do idealismo fichteano conduz a sequência da exposição da Doutrina da ciência pelo seguinte caminho: Eu e não-Eu determinam-se reciprocamente. Ipso facto, pode-se falar na existência de uma relação entre eles. Quando o não-Eu determina o Eu, isto é, quando o Eu comporta-se (põese) passivamente diante do não-Eu, tem-se o fundamento da atividade teórica. No caso contrário, a atividade prática.

Segundo Fichte, para que o Eu possa determinar o não-Eu, é preciso que sua causalidade (Wirksamkeit) afete o não-Eu. Contudo, se o não-Eu está sob o controle do Eu, como apreendê-lo como não-Eu, isto é, como distinto, como o outro do Eu? Por outro lado, se houver resistência do não-Eu em relação ao controle do Eu, como seria possível fixar o Eu como absolutamente independente e auto-determinante? ${ }^{12}$

Fichte busca resolver essas aparentes contradições estabelecendo que o Eu é infinito em um sentido e finito em outro. Na parte teórica de sua doutrina, o filósofo assinala que o Eu infinito se delimita como sujeito e, por consequência, põe um objeto (porquanto sem essa delimitação não há como se falar em infinitude). Ou seja, o Eu é infinito (é quem põe sujeito e objeto) e finito (sujeito que se defronta com o objeto) ao mesmo tempo. É a imaginação produtiva do Eu (cf. FICHTE, 1980, p. 113 - I, 215) a faculdade responsável por operar essa alternância, isto é, é ela quem produz a realidade.

Para o entendimento que apreende essa produção ${ }^{13}$, no entanto, o objeto produzido pela imaginação aparece como distinto do Eu, como uma produção "não consciente" (cf. FICHTE, 1980, p. 122 e ss. - I, 230 e ss.). Apenas a reflexão filosófica - a razão - permite ao sujeito entender-se como causa (Ursache) do objeto $^{14}$. Assim, ao reconhecer-se como fundamento da realidade (pois, só é possível falar em "realidade" a partir da posição do Eu), ele pode determinar o não-Eu de acordo com sua vontade. Este é o princípio de sua atividade prática. Para os intentos desse artigo, é nele que convém se debruçar mais detidamente.

Na fundação da ciência do prático, a alternância ente o Eu finito e infinito reaparece. Agora, o Eu é infinito na medida em que sua atividade prática é um

\footnotetext{
12 Tal como explica Dudley, a contradição que se apresenta aqui é a de que, "para se auto-determinar, o sujeito deve ser 'infinito', não limitado por qualquer coisa externa a si mesmo. Mas, para ser um Eu, deve ser 'finito', limitado por um mundo externo do qual ele se distingue a si mesmo" (DUDLEY, 2007, p. 93).

$13 \mathrm{O}$ entendimento (Verstand), em Fichte, se define como "a imaginação fixada pela razão", isto é, a faculdade na qual os produtos da imaginação adquirem realidade. $O$ entendimento não produz, mas apenas conserva aquilo com o qual se defronta.

${ }^{14}$ De fato, "na reflexão natural, oposta à reflexão transcendental-filosófica artificial, em virtude de suas leis, só se pode retroceder até o entendimento, e nesse, então, se encontra certamente algo dado à reflexão, como matéria (Stoff) da representação; mas não se toma consciência da maneira como o mesmo chegou ao entendimento. Daí nossa firme convicção da realidade de coisas fora de nós, e sem qualquer intervenção nossa, porque não tomamos consciência da faculdade de sua produção" (FICHTE, 1980, p. 124-I, 234).
}

SANTOS, Vinícius dos. Subjetividade, liberdade e ação: aproximações entre a ontologia fenomenológica de Sartre e o idealismo transcendental de Fichte. Griot : Revista de Filosofia, Amargosa, Bahia, v.16, n.2, p.81-101, 
impulso (Trieb), um esforço (Streben) permanente para conformar o não-Eu à sua vontade infinita. É finito, porquanto o movimento do sujeito de lançar-se para fora de si, de se dirigir ao mundo, é sempre incompleto, pois há resistência do não-Eu. Em outros termos, ao mesmo tempo em que age permanentemente sobre o mundo de forma a transformá-lo de acordo com seu intento - enquanto um ansiar (cf. FICHTE, 1980, p. 165 - I, 307) -, sua atividade é parcialmente frustrada, dando origem a um sentimento de delimitação que faz com que o esforço seja sempre recomeçado.

Pode-se dizer que todo o segredo da ação prática, na visão de Fichte, reside na compreensão desse choque, desse coligir entre opostos que promove um travo [Anstoss] à atividade infinita do Eu: "O objeto do sentimento de delimitação é algo real; o do ansiar não tem realidade, mas, em decorrência do ansiar, deve tê-la, pois este se dirige à realidade. Ambos são opostos um ao outro, porque por um deles o eu se sente delimitado, esforça-se pelo outro, para sair da delimitação" (FICHTE, 1980, p. $165-\mathrm{I}, 306)^{15}$.

Sendo assim, se, na atividade teórica, o não-Eu se apresenta ao Eu como objeto de conhecimento, objeto a ser desvelado na sua essência, na atividade prática, isto é, na ação moral, o objeto se apresenta ao sujeito como obstáculo a ser superado: "o eu sente-se impelido (...) para fora de si mesmo" (FICHTE, 1980, p. 159 - I, 296). Disso decorre que, para Fichte, o conhecimento teórico tem primazia filosófica sobre a atividade prática, enquanto esta última tem primazia ontológica sobre o primeiro ${ }^{16}$. Com efeito, a força que se opõe ao Eu na ação

é independente do eu segundo seu ser e sua determinação, a qual, no entanto, a faculdade prática do eu ou seu impulso (Trieb) à realidade esforça-se por modificar; mas é dependente de sua atividade ideal, de sua faculdade teórica; ela só é para o eu na medida em que é posta por ele e, fora disso, não é para o eu. Apenas na medida em que é referido à faculdade prática do eu, algo tem realidade independente; na medida em que é referido à teórica, esse algo está apreendido no eu, contido em sua esfera, submetido a suas leis de representação (FICHTE, 1980, p. 151 - I, $281-2)^{17}$.

\footnotetext{
15 Ao final da Doutrina da Ciência, Fichte arrematará: “A harmonia está aí, e surge um sentimento de agrado, que aqui é um sentimento de contentamento (Zufriedenheit), de preenchimento, total perfeição (que, porém, só dura um momento, por causa do ansiar, que necessariamente retorna)" (FICHTE, 1980, p. 176 - I, 328).

16 "O antagonismo do Eu prático condicionante e do eu teórico condicionado repete-se exatamente na relação do objeto ideal infinito e do objeto real finito. $O$ objeto de um dever ser infinito só pode ser a realização dum ideal infinito; e este só pode enveredar pelo caminho da eliminação duma realidade finita. Na verdade, a realidade tem de ser, efetivamente, eliminável, isto é, não pode ser uma realidade absoluta em si, mas somente uma realidade 'posta'. É justamente isto o que a Doutrina da Ciência teórica provou; não existe, de modo alguma uma realidade absoluta, mas só a realidade 'posta' dos objetos" (HARTMANN, 1983, p. 79).

17 "Portanto, aqui se confirma de novo, ou melhor, aqui aparece em toda sua clareza a proposição: sem idealidade, não há realidade, e vice-versa. Pode-se, portanto, dizer também: o fundamento último de toda consciência é uma ação recíproca do eu consigo mesmo mediante um não-eu a ser considerado de diferentes lados. Este é o círculo de que o espírito finito não pode sair, nem querer sair sem renegar a razão e desejar sua anulação" (FICHTE, 1980, p. 151 - I, 282).
}

SANTOS, Vinícius dos. Subjetividade, liberdade e ação: aproximações entre a ontologia fenomenológica de Sartre e o idealismo transcendental de Fichte. Griot : Revista de Filosofia, Amargosa, Bahia, v.16, n.2, p.81-101, 
Importante constatar que esta "dedução do Eu teórico a partir do prático que constitui o núcleo sistemático de toda a Doutrina da Ciência" (HARTMANN, 1983, p. 79). Declara Fichte a esse respeito:

\begin{abstract}
Através disso, finalmente, achamos também o ponto da unificação buscado, entre o ser absoluto, prático e inteligente do eu. - $\mathrm{O}$ eu exige abranger em si toda realidade e preencher a infinitude. Essa exigência tem necessariamente por fundamento a ideia do eu infinito, pura e simplesmente posto; e este é o eu absoluto, de que falamos. (Somente aqui torna-se plenamente claro o sentido da proposição: o eu põe a si mesmo pura e simplesmente. Nela não se trata, de modo algum, do eu dado na consciência efetiva; pois este nunca é pura e simplesmente, seu estado está sempre, imediata ou mediatamente, fundado por algo fora do eu; trata-se de uma ideia do eu, que tem de ser colocada necessariamente como fundamento de sua exigência prática infinita, mas que para nossa consciência é inalcançável, e por isso nunca pode aparecer imediatamente nela [mas mediatamente, sim, na reflexão filosófica].) (FICHTE, 1980, p. $149-\mathrm{I}, 277)^{18}$.
\end{abstract}

De fato, na vida prática é que finalmente se revela o motivo pelo qual o Eu põe o não-Eu: para realizar-se como liberdade, ser-para-si. "A essência do eu consiste em sua atividade" (FICHTE, 1980, p. 146 - I, 272). O Eu infinito, por um impulso que é sua própria realidade, deve (soll) infinitamente pôr o não-Eu - portanto, limitar-se como Eu finito, existência particular (Dasein), sujeito - para superá-lo ao infinito. A verdadeira perfeição é o esforço infinito rumo ao perfeito enquanto deverser, progressiva superação do dado.

Neste cenário, pode-se ainda assinalar, Deus não pode ser pensado como uma realidade em si, autônoma e independente, mas como a ordem moral do mundo ${ }^{19}$. Logo, a verdadeira religião é a ação moral, e o sujeito finito nada mais é, em sua atividade prática (em sua essência, portanto), que o mediador do Absoluto como Ideia (no sentido kantiano) a se realizar no infinito.

V

Como apontado no início, a filosofia sartriana identifica idealismo ao movimento de redução do ser ao conhecimento, tomando unilateralmente como

18 Seria a ideia de um Eu infinito inalcançável um retorno de Fichte às ideias ilusórias da dialética transcendental da primeira Crítica de Kant? É essa a leitura de Alexis Philolenko, para quem os quatro primeiros parágrafos da Doutrina da Ciência de 1794 representariam o desenvolvimento de uma dialética transcendental (cf. PHILOLENKO, 1999, p. 119).

${ }^{19}$ Apoiando uma interpretação metafísica da teoria fichteana, Sofia Vanni Rovighi, em sua Storia dela filosofia moderna, observa: "R. Kroner diz que no terceiro princípio, Fichte exprime as relações entre Deus (Eu absoluto), eu (consciência humana limitada) e mundo: Deus se autolimita para tornar-se uma consciência finita, que tem um objeto (mundo) diante de si. Na segunda e terceira partes da Grundlage, Fichte busca demosntrar como e porque as relações entre Eu absoluto, eu humano e mundo se põem deste modo. Na primeira parte, Fichte afirmou que na origem do real está o Eu com sua atividade - (...) -; na segundo parte, questiona-se como se concilia com este princípio o fato de que o objeto em apareça como dado; como se explica a representação. E antes de proceder à solução do problema, indica o método que seguirá [o método sintético que, a partir do terceiro princípio, permite a compreensão das atividades teórica e prática do Eu - V.S.]" (ROVIGHI, 1976, p. 738-9).

SANTOS, Vinícius dos. Subjetividade, liberdade e ação: aproximações entre a ontologia fenomenológica de Sartre e o idealismo transcendental de Fichte. Griot : Revista de Filosofia, Amargosa, Bahia, v.16, n.2, p.81-101, 
modelo desse agenciamento o pensamento de Berkeley. Contudo, como pode se depreender da análise precedente, há nuances nada desprezíveis entre o esse est percipi do filósofo inglês e o idealismo alemão do século XIX. Com efeito, o leitor de Sartre não deve ter tido dificuldade em reconhecer certa familiaridade entre algumas conclusões de Fichte e aquelas que seriam desenvolvidas em $1943 \mathrm{em} \mathrm{O}$ ser e o nada. Para melhor explorar essas ligações "subterrâneas" (o adjetivo parece válido, na medida em que, conforme já mencionado, Sartre jamais se dispôs a explicitá-las), convém recuperar algumas das linhas de força através das quais este último molda o tema da subjetividade.

O ensaio de ontologia fenomenológica se inicia com a constatação de que a fenomenologia de Husserl forneceria a chave para a superação do realismo e do idealismo através do seu conceito de intencionalidade da consciência. Segundo Husserl, toda consciência é consciência de algo e, portanto, consciência e mundo são polos que não existem fora dessa relação, isto é, da fenomenalidade. Contudo, na visão de Sartre, Husserl, infiel ao seu princípio, teria recaído no idealismo ao definir o noema intencional (o objeto visado após a épokhè fenomenológica, isto é, como fenômeno-para-a-consciência) como um "irreal" do ato noético (o movimento intencional da consciência que visa um objeto-enquanto-transcendência na imanência da própria consciência) ${ }^{20}$.

O que Sartre procura, apoiando-se naquele conceito elementar, é o fundamento da relação ente consciência e mundo desde uma análise ontológica do fenômeno, de tal modo a precisamente construir uma filosofia imune às aporias idealistas husserlianas, o que significa igualmente dizer: que apreenda a realidade humana enquanto ser-no-mundo, ao modo que Heidegger define o termo ${ }^{21}$.

Primeiramente, Sartre assevera que o ser do conhecimento "não pode ser medido pelo conhecimento; ele escapa ao percipi" (SARTRE, 2007, p. 17), quer dizer, é um ser transfenomenal. Para o filósofo, a tese idealista só poderia prosperar caso houvesse uma realidade do Eu que pudesse transferir objetividade ao ser transcendente (é o movimento de Fichte, como visto). Entretanto, de acordo com o que Sartre defende desde sua primeira obra de destaque, A transcendência do ego, a consciência nada tem de substancial ${ }^{22}$. Sua existência reduz-se à sua aparição. Por isso, qualquer traço de imanência, qualquer índice reificador, deve ser descartado como obstáculo ao caráter intencional da consciência. Ela, portanto, é um vazio, um "vento" que se lança a um mundo que aparece inteiramente fora dela. A exemplo de Fichte, a consciência sartriana é um puro ato de sair-de-si.

Nesse sentido, ela tampouco se caracteriza como "um modo de conhecimento particular, [que poderia ser] denominado sentido íntimo ou conhecimento de si. Ela é a dimensão de ser transfenomenal do sujeito" (SARTRE, 2007, p. 17). Contudo, a

\footnotetext{
${ }^{20}$ Vale destacar que é a não degradação da transcendência do objeto na imanência da consciência que permite à fenomenologia husserliana superar a noção clássica de representação (cf. LYOTARD, 1967, p. 33-4).

${ }^{21}$ Para Sartre, o concreto "só pode ser a totalidade sintética, da qual tanto a consciência como o fenômeno são apenas momentos. $O$ concreto é o homem no mundo, com aquela união específica do homem ao mundo que Heidegger, por exemplo, denomina "ser-no-mundo" (SARTRE, 2007, p. 37-8). ${ }^{22}$ Em 1934, Sartre a definia como um "campo transcendental sem sujeito" (cf. SARTRE, 2003, p. 19 e ss.).
}

SANTOS, Vinícius dos. Subjetividade, liberdade e ação: aproximações entre a ontologia fenomenológica de Sartre e o idealismo transcendental de Fichte. Griot : Revista de Filosofia, Amargosa, Bahia, v.16, n.2, p.81-101, 
necessidade de fundar este ser transfenomenal para além do primado do conhecimento exige uma nova constatação: “a condição necessária e suficiente para que uma consciência cognoscente seja consciência de seu objeto é que ela seja consciência dela mesma como sendo este conhecimento" (SARTRE, 2007, p. 18). Do contrário, toda consciência de um objeto se ignoraria enquanto consciência de algo. Seria uma "consciência inconsciente", o que é um absurdo. Para Sartre, toda consciência é sempre consciência "de ponta a ponta". Todavia, essa consciência que se reconhece como consciência posicional de um objeto também reclamaria, por sua vez, uma nova consciência. Se assim não o fosse, o mesmo problema - o da consciência que ignora sua posição - reapareceria em outro nível; e assim sucessivamente.

Segundo o filósofo, o único modo de evitar essa regressão permanente de uma "consciência da consciência" é admitir que toda consciência que põe um objeto é também, ao mesmo tempo, consciência não-posicional de si mesma. "A consciência de si não é dualidade (un couple). Se queremos evitar a regressão ao infinito, é preciso que ela seja relação imediata e não-cognitiva de si a si" (SARTRE, 2007, p. 19).

Dito de outro modo, para Sartre, não há primado da reflexão sobre a consciência refletida. Não é a primeira que revela a última, mas, pelo contrário, é a consciência não-reflexiva, não-tética, que torna possível a reflexão: "há um cogito pré-reflexivo que é a condição do cogito cartesiano" (SARTRE, 2007, p. 19). Sartre representará essa consciência imediata como "consciência (de) si", o parêntese buscando assinalar que se trata de uma relação vivida imediatamente: a consciência (de) si é consciência-si, é um absoluto (cf. SARTRE, 2007, p. 22-3).

A aproximação entre os entendimentos de Sartre e Fichte, nessa passagem, salta aos olhos. Tanto o Eu fichteano quanto a consciência (de) si sartriana são pensados como instâncias fundamentais, cuja realidade é imediata ou intuitivamente vivida e que supera, por conseguinte, coordenadas exclusivamente epistemológicas. Ambas remetem ao domínio absoluto e irredutível da existência, de uma subjetividade não substancial, não-reificada.

Nesse sentido, não parece despropositado afirmar que a crítica seguinte de Sartre ao sujeito cartesiano, a partir da qual aquele filósofo intenta fixar uma noção de subjetividade não-essencialista, poderia ser quase inteiramente subscrita por Fichte:

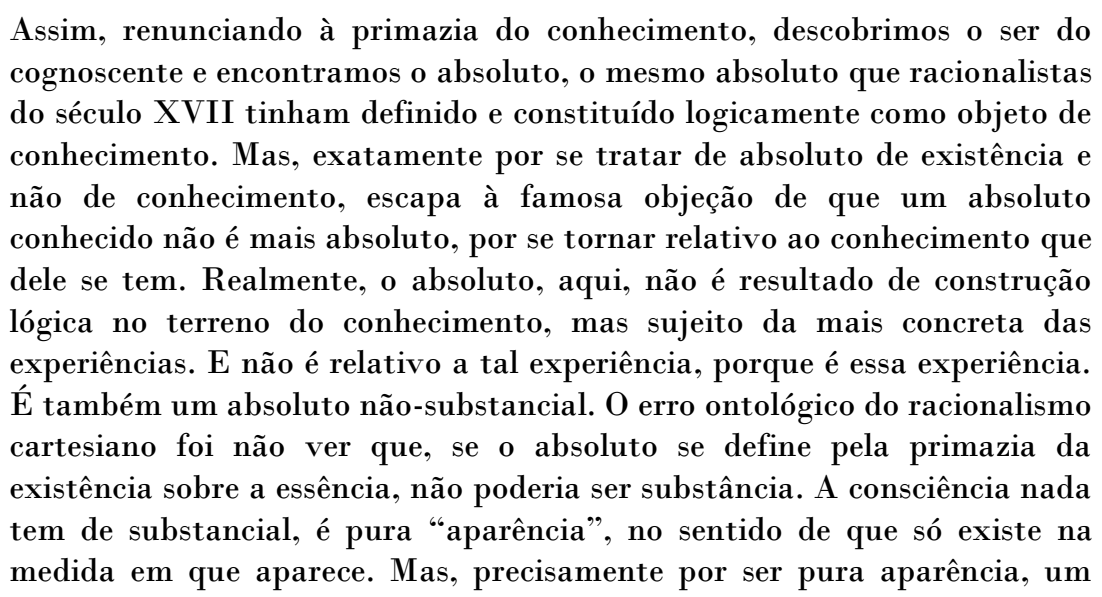

SANTOS, Vinícius dos. Subjetividade, liberdade e ação: aproximações entre a ontologia fenomenológica de Sartre e o idealismo transcendental de Fichte. Griot : Revista de Filosofia, Amargosa, Bahia, v.16, n.2, p.81-101, 
vazio total (já que o mundo inteiro se encontra fora dela), por essa identidade que nela existe entre aparência e existência, a consciência pode ser considerada o absoluto (SARTRE, 2007, p. 22-3).

VI

Foi assinalado ao final da seção anterior que o último excerto destacado de $O$ ser e o nada poderia ser quase inteiramente subscrito por Fichte. $O$ uso advérbio, convém observar, não representa nenhuma condescendência. Pelo contrário, ele se impõe por um detalhe essencial, através do qual Sartre visa conservar certo realismo ontológico que, por assim dizer, contrabalancearia a aproximação ao idealismo através da qual pensa a subjetividade: trata-se da ideia de que o mundo todo se encontra fora da consciência.

Importa reforçar: de acordo com Sartre, o conhecido não pode ser absorvido pelo conhecimento, quer dizer, o ser do percipi jamais se reduz ao ser do percipiens. Porque é um néant - busca de fundamento, como a sequência de $O$ ser e o nada irá mostrar - "o ser transfenomenal da consciência não poderia fundar o ser transfenomenal do fenômeno" (SARTRE, 2007, p. 26). Se é assim, cabe, então, questionar: qual é o ser do fenômeno?

Já no início do ensaio de ontologia fenomenológica, Sartre demarca que o fenômeno, isto é, aquilo que aparece a uma consciência, é uma "plena positividade", cuja “essência é uma 'aparecer' que já não se opõe ao ser, mas que, pelo contrário, é sua medida" (SARTRE, 2007, p. 12). Contudo, é preciso ter claro que, se a aparência é a essência do fenômeno, na medida em que a revela, uma e outra não se confundem. Retomando outra tese husserliana, a de que a coisa se mostra à consciência sempre por "perfis" (Abschattungen) - o que torna a fenomenalidade inesgotável -, Sartre distingue entre o fenômeno-de-ser - a aparição perfilada de algo - e o ser-do-fenômeno - o qual a aparição fenomenal, justamente por seu caráter inesgotável, reclama:

O fenômeno de ser exige a transfenomenalidade do ser. Isso não significa que o ser se encontra escondido atrás dos fenômenos (vimos que o fenômeno não pode esconder o ser) - nem que o fenômeno seja uma aparência que remete a um ser distinto (é enquanto aparência que o fenômeno é, ou seja, que ele se indica sobre o fundamento do ser). O que está implicado pelas considerações precedentes é que o ser do fenômeno, ainda que extensivo ao fenômeno, deve escapar à condição fenomenal que é a de não existir que na medida em que se revela - e que, por conseguinte, ele transborda e funda o conhecimento que se apreende dele (SARTRE, 2007, p. 16).

Assim, na contramão do pensamento fichteano, Sartre visa garantir a autonomia do ser do objeto em face da consciência - o ser, nesse sentido, é de trop -, ao mesmo tempo em que assegura o vínculo fenomenológico entre ambos - o que, como assinalado, não estava em questão para Fichte, para quem não há realidade independente da consciência.

Para promover aquele agenciamento, Sartre, recuperando Santo Anselmo e Descartes, se vale do expediente de uma prova ontológica capaz de ratificar a defesa

SANTOS, Vinícius dos. Subjetividade, liberdade e ação: aproximações entre a ontologia fenomenológica de Sartre e o idealismo transcendental de Fichte. Griot : Revista de Filosofia, Amargosa, Bahia, v.16, n.2, p.81-101, 
daquela autonomia sem dispensar a noção de intencionalidade. Afinal, se como reza a cartilha fenomenológica, toda consciência é consciência de alguma coisa, "isso significa que a transcendência é estrutura constitutiva da consciência. Ou seja, a consciência nasce tendo por objeto um ser que não é ela" (SARTRE, 2007, p. 28). Em outros termos, o próprio ser da consciência, enquanto intencionalidade, exige um ser diferente dela; um ser que não seja posto por ela, como o Eu põe o não-Eu em Fichte, mas que exista já no momento em que se fenomenliza. Nesse sentido, fazendo eco à Refutação ao idealismo de Kant em sentido oposto ao fichteano, Sartre assinala:

\begin{abstract}
O que se pode chamar propriamente de subjetividade é a consciência (de) consciência. Mas é preciso que esta consciência (de ser) consciência se qualifique de algum modo, e ela só pode se qualificar como intuição reveladora, caso contrário, nada será. Ora, uma intuição reveladora pressupõe algo revelado. A subjetividade absoluta só pode se constituir frente a algo revelado, a imanência não pode se definir exceto na captação de algo transcendente. Parece que deparamos aqui com um eco da refutação kantiana do idealismo problemático. Mas melhor pensar em Descartes. Estamos no plano do ser, não do conhecimento; não se trata de mostrar que os fenômenos do sentido interno presumem a existência de fenômenos objetivos e espaciais, mas que a consciência implica em seu ser um ser não-consciente e transfenomenal. Em particular de nada serviria replicar que, de fato, a subjetividade pressupõe a objetividade e se constitui a si ao constituir o objetivo: já vimos que a subjetividade é incapaz disso. Dizer que a consciência é consciência de alguma coisa é dizer que deve se produzir como revelação-revelada de um ser que ela não é e que se dá como já existente quando ela o revela (SARTRE, 2007, p. 28).
\end{abstract}

Nota-se, destarte, que, enquanto Fichte enxerga na "fraqueza", por assim dizer, da "refutação kantiana ao idealismo problemático", uma via para a consolidação de um idealismo consequente, isto é, ciente do Eu como seu princípio, Sartre enxerga na prova ontológica uma via para escapar completamente ao idealismo. $\mathrm{Ou}$, como insinuado mais acima, para contrabalanceá-lo com certo teor de realismo que, a seu ver, representa o único modo possível de fidelidade à subjetividade, ao cogito.

Na sequência, importa indicar que, do ser do fenômeno, cuja existência fora provada pela análise do próprio ser da consciência enquanto intencionalidade, nada se pode dizer: não há relação no seio do ser, não há reflexão, distanciamento de si a si. Ao contrário da consciência, que é ser-para-si, o ser do fenômeno é identidade perfeita consigo mesmo. Ele é o que é, é em-si.

Todo o encadeamento argumentativo subsequente de $O$ ser e o nada, aliás, representa a tentativa de esclarecer os meandros da relação entre Para-si e Em-si, ou seja, descrever fenomenologicamente a realidade humana enquanto ser-no-mundo. Se o Em-si é identidade plena, pura positividade, o ser da consciência só poderá ser definido como nada (néant), como “descompressão de ser" (SARTRE, 2007, p. 32, 110), como "o ser que se determina a si mesmo a existir como não podendo coincidir consigo mesmo" (SARTRE, 2007, p. 114).

Neste momento, no entanto, parece vir à tona uma contradição: como esclarecer o surgimento desse Nada em face da prévia definição do Em-si? Intrigante constatar que a exígua resposta de Sartre limita-se a dizer que esse "buraco de ser" é

SANTOS, Vinícius dos. Subjetividade, liberdade e ação: aproximações entre a ontologia fenomenológica de Sartre e o idealismo transcendental de Fichte. Griot : Revista de Filosofia, Amargosa, Bahia, v.16, n.2, p.81-101, 
uma "queda do Em-si rumo a si"; dito de outro modo, trata-se de um "ato perpétuo através do qual o Em-si se degrada em presença de si" (SARTRE, 2007, p. 115). Com efeito, este "ato ontológico" ou "acontecimento absoluto", que dá origem ao Para-si, não implica defender que o Nada participa do ser, ou que é seu contemporâneo lógico (ao modo de Hegel). O próprio vocabulário empregado por Sartre ("acontecimento absoluto") indica que o surgimento do Nada é imotivado. A contingência primeira do ser, já afirmada na Introdução da obra ${ }^{23}$, afeta todas as demais regiões ontológicas e, nesse domínio - da ontologia, do ser "engajado" no mundo - em nada se pode avançar na questão do surgimento da realidade humana ${ }^{24}$. Entretanto, o ser não depende do nada para existir. Pelo contrário, é o nada que se atrela ao ser, que busca seu fundamento no ser. Mas, ao fazê-lo, essa relação jamais adquire o estatuto de mútua reciprocidade: o Nada é sempre exterior (dehors) ao ser.

Disso decorre outra diferença relevante entre Sartre e Fichte: não há síntese possível entre Para-si e Em-si - como na relação entre Eu e não-Eu de Fichte -, isto é, mútua determinação, porquanto o Para-si não põe o Em-si, não é sua causa (cf. FICHTE, 1980, p. 135 - I, 250). Sendo assim, não há relação interna entre ambos e, consequentemente, dialética possível. Este aspecto é relevante, porquanto em Fichte a dialética começa a superar o caráter restritivo da crítica kantiana, que a detectava como uma antinomia insuperável da razão, para se insinuar como o modo de ser da própria razão (o ato de opor ao Eu um não-Eu exige uma relação sintética de superação da oposição) - gesto que terá seu coroamento definitivo com o idealismo absoluto hegeliano. Já em Sartre (de $O$ ser e o nada, ao menos), tudo se passa de outro modo: o não-ser não é negação determinada, mas o extremo oposto do ser, sua negação radical $^{25}$. Logo, não há cenário para a transformação da antítese inicial, síntese ou progresso, mas tão somente uma relação entre o Mesmo e o Outro. Na melhor das hipóteses, o que se tem é uma dialectique manquée, na qual um dos termos tem o privilégio sobre o outro, e o conserva à distância na exata medida em que tenta - em vão, como ser verá - incorporá-lo.

\section{VII}

Entretanto, cumpre que o expediente sartriano pelo qual o Em-si é posto fora da consciência, se impede uma assimilação completa, tampouco é suficiente para afastar Sartre definitivamente (como o próprio defende) do idealismo, pelo menos ao

23 “Enfim - essa será nossa terceira característica - o ser-em-si é. Isso significa que o ser não pode ser
derivado do possível, nem reconduzido ao necessário. A necessidade diz respeito à ligação de
proposições ideais, mas não àquelas dos existentes. Um existente fenomenal não pode jamais ser
derivado de um outro existente, enquanto ele é existente. É o que se chama de contingência do ser-em-
si. Mas, o ser-em-si tampouco pode ser derivado de um possível. O possível é uma estrutura do para-si,
quer dizer, pertence à outra região de ser. O ser-em-si não é jamais, nem possível, nem impossível; ele
ê" (SARTRE, 2007, p. 33).
24 Este problema, dirá Sartre ao final de $O$ ser e o nada, remete à Metafísica enquanto disciplina
hipotética (cf. SARTRE, 2007 , p. 665 e ss.).
25 Vale destacar: o que permite a Sartre conservar esse dualismo sem que os termos se anulem é
precisamente a tese de que o nada sempre permanece exterior ao ser.

SANTOS, Vinícius dos. Subjetividade, liberdade e ação: aproximações entre a ontologia fenomenológica de Sartre e o idealismo transcendental de Fichte. Griot : Revista de Filosofia, Amargosa, Bahia, v.16, n.2, p.81-101, 
modo fichteano ${ }^{26}$. Antes, como sugerido, a forma pela qual Sartre visa superar realismo e idealismo, por via de uma ontologia fenomenológica, é compor uma síntese de ambas as vertentes. Síntese que, não obstante a visada "anti" ou "nãodialética" de $O$ ser e o nada, conserva traços das filosofias que pretende superar, como a intuição da consciência-de-si enquanto pura atividade já comprovou. Essa possível aproximação com o idealismo fichteano se verifica novamente no âmbito prático da filosofia sartriana, isto é, em sua teoria da ação.

A prévia definição da consciência como o outro do ser, isto é, como não-ser ou como nada, permite a Sartre mobilizar a noção heideggeriana de nadificação (néantisation) como o modo de ser da relação entre Para-si e Em-si. "O Para-si só pode sustentar a nadificação determinando-se a si mesmo como uma falta-de-ser. (...) Assim, a nadificação sendo nadificação de ser, representa a ligação original entre o ser do Para-si e o ser do Em-si" (SARTRE, 2007, p. 121-2).

Porque é defaut d'être, o sentido de ser do Para-si é precisamente preencher esse vazio ontológico. A nadificação do ser é, destarte, o movimento pelo qual o Para-si se lança ao Em-si no intuito de integrá-lo em uma síntese, constituir um SerEm-si-Para-si. A realidade humana, em outras palavras, é desejo-de-ser, isto é, desejo de ser si mesma ao modo do Em-si. Entretanto, conforme indicado na seção precedente, porque não há relação interna entre ambos, a realização da plenitude ontológica jamais se realiza. Ou seja, porque Em-si e Para-si são termos contraditórios, porque o Para-si não é causa do Em-si, não afeta seu ser, ela é um desejo frustrado; ato contínuo, permanentemente renovado.

Assim, a nadificação se vincula à permanente possibilidade do Para-si significar o mundo, dar sentido existencial a seu fracasso ontológico. Este é o núcleo da ideia sartriana de que a realidade humana é radicalmente livre, de que sua existência precede sua essência. A liberdade, em Sartre, é precisamente esse poder de revestir o Em-si de uma camada de significado que ele, por definição, não possui. E, precisamente por não possui-lo, a liberdade do Para-si nesta tarefa é "total e infinita" (SARTRE, 2007, p. 576). Não há, a priori, nada que determine a ação nadificadora da consciência e, por conseguinte, seu trabalho de constituição de sentido $^{27}$. Pelo contrário, a facticidade do ser torna-se ocasião do exercício da liberdade, situação que delimita, sem determinar, o campo de ação do Para-si ${ }^{28}$. Esta ação, porém, é interminável. A finitude do existente aponta sempre para o infinito (Ser-Em-si-Para-si) enquanto impossível-possibilidade, paradoxo constitutivo, paixão inútil, mas inescapável. Tal como em Fichte, a ação é, também para Sartre, o meio de desvelamento do sujeito para si mesmo.

${ }^{26}$ Nossa posição, neste quesito, é similar àquela defendida por Daniel Breazeale (cf. BRAZEALE. In: WAIBEL et al.:, 2010, p. 286).

${ }^{27}$ Essa liberdade radical, vale notar, é o que permite, para Sartre, a existência de uma consciência imaginante. Bem entendida, porém, a imaginação aqui não produz o real, como em Fichte, mas o ultrapassa, ainda que sem jamais desvincular-se completamente dele (cf. SARTRE, 2007b).

28 A relação com outras consciências surge, na Terceira Parte de $O$ ser e o nada, como fator complicador deste esquema. Contudo, não obstante o outro representar um limite concreto à liberdade absoluta do Para-si, isto é, no plano existencial no qual a liberdade é liberdade-em-situação, ele jamais a anula do ponto de vista ontológico.

SANTOS, Vinícius dos. Subjetividade, liberdade e ação: aproximações entre a ontologia fenomenológica de Sartre e o idealismo transcendental de Fichte. Griot : Revista de Filosofia, Amargosa, Bahia, v.16, n.2, p.81-101, 
Por isso, não obstante as disparidades de propósito entre o idealismo transcendental e a ontologia fenomenológica, há novamente uma nítida proximidade entre o enquadramento sartriano da ação e aquele demarcado por Fichte. Em ambos os casos, trata-se para o sujeito de superar o dado, enquanto seu outro (não-Eu ou Em-si), em direção a um fim sempre reposto porque e enquanto inalcançável. Desse modo, a ação representa a assunção da liberdade como princípio máximo da subjetividade enquanto fonte de constituição de sentido do real. Em Sartre, tanto quanto em Fichte, o ser do homem reduz-se ao fazer (cf. SARTRE, 2007, p. 475) ${ }^{29}$.

\section{VIII}

A guisa de conclusão é possível afirmar, diante do exposto, que, por um lado, o idealismo fichteano parece ser mais consequente que a ontologia fenomenológica sartriana, porquanto estabelece uma relação interna entre o Eu finito e o não-Eu que legitimaria a posição da subjetividade como puro ato livre, isto é, capaz conferir sentido ao mundo do qual é causa (Ursache), justamente por ser sua causa.

Quer dizer, ao fixar uma relação de exterioridade, não-dialética, entre o Parasi e o Em-si, em Sartre, o sentido fornecido pela consciência não afeta o ser das coisas, mas imprime nele apenas uma camada superficial de significação. E, do mesmo modo, tampouco afeta o ser (ou o nada-de-ser) da consciência. De fato, em Fichte, o sentido do não-Eu só existe na medida em que este é posto pelo Eu. Para Sartre, contudo, é precisamente a independência do Em-si que permite ao Para-si se projetar como uma perpétua tentativa de incorporá-lo, isto é, buscar nele seu fundamento.

Do ponto de vista de um idealismo apoiado em Fichte, poderia se constatar um descompasso, na obra de Sartre, entre o plano existencial (o sujeito como fonte de sentido) e o ontológico (a relação de completa exterioridade entre Para-si e Emsi); na melhor das hipóteses, uma dificuldade de composição entre ambos. É o que se explicita, por exemplo, quando Sartre declara que o conhecimento, enquanto modo de o Para-si se dirigir ao Em-si, em nada altera os seres em relação ${ }^{30}$. Ou seja, encaminha-se no sentido contrário de Fichte, para quem, como explicado, o conhecimento estabelece uma dialética entre Eu e não-Eu na medida em que, através dele, o não-Eu se impõe ao Eu que se modifica e, nessa relação, abre caminho para a conformação do não-eu ao Eu por meio da razão prática.

Por outro lado, no entanto, a se guiar por Sartre, a ontologia fenomenológica tem a vantagem - trazida justamente seu viés fenomenológico - de não precisar se ocupar com o surgimento do objeto para a consciência porque, livre do horizonte demarcado pelo kantismo, pode tomar como fato a autonomia do ser, sublinhando

\footnotetext{
29 "A fonte de toda realidade é o eu, pois ele é o imediato e o pura e simplesmente posto. Só pelo eu e com o eu está dado o conceito de realidade. Mas o eu é porque se põe e põe-se porque é. Portanto, pôr-se e ser são o mesmo. Mas o conceito de pôr-se e o de atividade em geral são, por sua vez, o mesmo. portanto, toda realidade é ativa e todo ativo é realidade" (FICHTE, 1980, p. 69 - I, 133).

30 Conforme o filósofo, a relação cognitiva é uma relação de presença do Para-si ao Em-si. Consequentemente, "o fenômeno original de conhecimento não acrescenta nada ao ser e não cria nada. Por ele o ser não se enriquece, pois o conhecimento é negatividade pura, que faz apenas com que haja ser" (SARTRE, 2007, p. 215).
}

SANTOS, Vinícius dos. Subjetividade, liberdade e ação: aproximações entre a ontologia fenomenológica de Sartre e o idealismo transcendental de Fichte. Griot : Revista de Filosofia, Amargosa, Bahia, v.16, n.2, p.81-101, 
que o real não se reduz à representação do Eu. Com efeito, em Fichte, o movimento de finitude do Eu absoluto, isto é, de surgimento do real, através do qual ele põe um Eu finito e um não-Eu, sujeito e objeto, é um passo obscuro e remete a uma passagem truncada da dedução sistemática da primeira versão da Wissenschaftslehre ${ }^{31}$. Não por acaso, aliás, esse é um dos pontos nos quais a filosofia alemã posterior, a começar por Schelling, concentrará sua crítica. Para Sartre, no entanto, é precisamente aquela autonomia, anverso necessário da intencionalidade da consciência, que autoriza a filosofia a descrever a relação entre consciência e ser sem abstraí-los, sem reduzir um ao outro, isto é, abordar a realidade humana em sua concretude, como ser-no-mundo.

\footnotetext{
31 Christian Iber nota, nessa linha: "O problema permanente da Doutrina da Ciência de Fichte é o esclarecimento da estrutura e constituição da unidade entre auto-relação imediata e auto-relação refletida do Eu, pois absolutidade e ser-para-si do Eu parecem se excluir mutuamente. Sem dúvida, está claro que fichte diferencia uma consciência imediata do Eu de si mesmo (o que ele chamará mais tarde de intuição intelectual) de uma consciência refletida e distanciada do Eu de si mesmo (o que ele chamará mais tarde de conceito)" (IBER. In: IBER, 2007, p. 30). É essa consciência refletida do Eu que exige a posição do não-Eu como obstáculo a ser superado pela razão prática.
}

SANTOS, Vinícius dos. Subjetividade, liberdade e ação: aproximações entre a ontologia fenomenológica de Sartre e o idealismo transcendental de Fichte. Griot : Revista de Filosofia, Amargosa, Bahia, v.16, n.2, p.81-101, 


\section{Referências bibliográficas}

BREAZEALE, Daniel. How to make an existentialist? In search of a shortcut from Fichte to Sartre. In: WAIBEL, Violetta L. et al. (ed.). Fichte and the phenomenological tradition. Berlin: De Gruyter, 2010.

DUDLEY, Will. Understanding German Idealism. Stocksfield: Acumen, 2008.

FICHTE, Johann Gottlieb. A Doutrina-da-ciência de 1794. In: Col. Os Pensadores.

Trad. Rubens Rodrigues Torres Filho. São Paulo: Abril Cultural, 1980 (Science of Knowledge - with the first and second introducitons. Edited and translated by Peter Heath and John Lacs. Cambridge: Cambridge University Press, 1991; Grundlage der gesammten Wissenschaftslehre. In: Sämmtliche Werke. Erste Abtheilung - zur theorischen Philosophie. Erster Band. Berlin: De Gruyter, 1965).

. Sobre o conceito da doutrina-da-ciência ou da assim chamada

filosofia. In: Col. Os Pensadores. Trad. Rubens Rodrigues Torres Filho. São Paulo: Abril Cultural, 1980.

HARTMANN, Nicolai. A filosofia do Idealismo Alemão. 2a edição. Trad. José Gonçalves Belo. Lisboa: Fundação Calouste Gulbenkian, 1983.

IBER, Christian. O conceito de Eu em Fichte segundo os $\S \S 1-3$ do Fundamento de toda a Doutrina da Ciência, de 1794-95. In: IBER, Christian et al. Dialética do eu e não-eu em Fichte e Schelling. Fortaleza: Edições UFC, 2007.

KANT, Immanuel. Crítica da Razão Pura. $5^{\text {a }}$ edição. Trad. Manuela Pinto dos Santos e Alexandre Fradique Morujão. Introdução e notas Alexandre Fradique Morujão. Lisboa: Fundação Calouste Gulbenkian, 2001.

LYOTARD, Jean-François. A Fenomenologia. Trad. Mary Amazonas Leite Barros. São Paulo: Difusão Européia do Livro, 1967.

PHILONENKO, Alexis. La liberté humaine dans la philosophie de Fichte. Paris: Vrin, 1999.

ROCKMORE, Tom. Remarques sur Fichte et Sartre. In: Journal of French and Francophone Philosophie. Vol. 7, no 3, 1995, p. 208-23.

ROVIGHI, Sofia Vanni. Storia dela filosofia moderna - dalla rivoluzione scientifica a Hegel. Brescia: Editrice La Scuola, 1976.

SARTRE, Jean-Paul. La transcendance de l'ego et autres textes phénoménologiques. Textes introduits et anotés par Vincent de Coorebyter. Paris: Vrin, 2003.

L'Être et le Néant - essai d'ontologie phénoménologique. Édition

corrigée avec index par Arlette Elkä̈m-Sartre. Collection Tel. Paris: Gallimard, 2007.

L’imaginaire - psychologie phénoménologique de l'imagination.

Édition révue et présentée par Arlette Elkaïm-Sartre. Paris: Gallimard, 2007b.

TORRES FILHO, Rubens Rodrigues: $O$ espírito e a letra - a crítica da imaginação pura em Fichte. São Paulo: Editora Ática, 1975.

Autor(a) para correspondência: Vinícius dos Santos, Universidade Federal da Bahia Faculdade de Filosofia e Ciências Humanas, R. Prof. Aristídes Novis, 197, Federação, CEP 40210-909, Salvador BA, Brasil.vsantos1985@gmail.com

SANTOS, Vinícius dos. Subjetividade, liberdade e ação: aproximações entre a ontologia fenomenológica de Sartre e o idealismo transcendental de Fichte. Griot : Revista de Filosofia, Amargosa, Bahia, v.16, n.2, p.81-101, 